\title{
Comparison of Mechanical and Microstructural Properties of Fly Ash Geopolymer in Water and Chloride Environment
}

\author{
Sharon Robert ${ }^{1, a}$, Idawati Ismail ${ }^{2, b^{*}}$, Raudhah Ahmadi ${ }^{3, c}$, \\ Nur Amalina Shairah binti Abdul Samat ${ }^{4, d}$ \\ 1,2,3,4Faculty of Engineering, Universiti Malaysia Sarawak, 94300 Kota Samarahan, \\ Sarawak, Malaysia \\ asharonrobert2111@gmail.com, b*iidawati@unimas.my, caraudhah@unimas.my, \\ dasnamalina@unimas.my
}

Keywords: chloride, curing regime, durability, fly ash geopolymer

\begin{abstract}
In cement industry, the emissions of greenhouse gases specifically $\mathrm{CO}_{2}$ from the clinker production led to the need of alternative binders. Geopolymer binder whose precursors are sourced from industrial by-products such as fly ash that are rich is silica and alumina has been studied extensively in the past decades. Chloride attack is one of the threats to concrete structures. Analysis at microstructural level needs to be studied carefully before this binder can be used with confidence. This study attempts to compare the properties of fly ash geopolymer binder when exposed in water and chloride solution. Fly ash geopolymer pastes were prepared using 12M sodium hydroxide $(\mathrm{NaOH})$ as activator. The pastes were tested under two separate curing conditions, i.e in ambient and in distilled water. Compressive strength test along with microstructure properties of samples cured at 7, 14 and 28 days were conducted via Universal testing machine, Fourier Transform Infra-Red (FTIR) spectroscopy and Scanning Electron Microscope with Energy-dispersive X-ray (SEM-EDX). After 28 days of curing, these samples were immersed in $10 \%$ sodium chloride $(\mathrm{NaCl})$ solution for another 56 days. Samples cured in ambient condition showed better mechanical performance than those in distilled water. Their differences in compressive strength were also seen consistent with the FTIR results. Samples exposed to $\mathrm{NaCl}$ and distilled water showed similar mechanical performance and microstructural properties. Based on SEM-EDX analysis, samples cured in ambient were rich in silica and alumina while the intensity of these compounds were observed to reduce when exposed to distilled water. Samples cured in ambient showed stronger intensity of Si/Al gel as compared to samples exposed to chloride environment and distilled water and these were consistent with the compressive strength results obtained. When immersed in water, concentration gradient changes in the liquid phases, leading to ions diffusion and causing decrement in strength and durability of the solids in fly ash geopolymer.
\end{abstract}

\section{Introduction}

Geopolymer binders have gained attention in helping to reduce cement dependency [1]. They are formed via chemical reactions between materials with high content of alumina and silica, simply known as solid aluminosilicate precursors, and alkaline solution [1]. The source of alkali acts as the soluble base activator that increases the strength of the alkali-activated binders [2]. Studies have shown geopolymer binders as good potential for the replacement of Ordinary Portland Cement (OPC) and could be more durable than concretes with OPC. However, lack in durability data requires more study should be conducted especially focusing on microstructural behavior.

Fly ash is one type of industrial coal combustion by-product which is released together with flue gases and captured through the dust compilation technique [3]. It contains alumina, iron, silica, and calcium as major components while magnesium, sulfur, potassium, sodium and carbon as minor components. Since fly ash is an aluminate-rich product, it is potentially suitable to replace OPC as supplementary cementitious material or as precursor for geopolymer. Therefore, this research will focus on the the microstructural aspect of fly ash geopolymer binder. 